\title{
The vomeronasal system, aggression, activity, and passive-avoidance learning in hooded rats
}

\author{
CHRISTOS MOUTZOUKIS, TIM DONOHOE, and B. MICHAEL THORNE \\ Mississippi State University, Mississippi State, Mississippi
}

\begin{abstract}
Muricidal behavior, irritability to handling, open-field activity, passive-avoidance learning, and weight change were measured in Long-Evans hooded rats after they had been subjected to olfactory bulb removal, cuts of the vomeronasal nerves, lateral olfactory bulb damage, or control operations. Bulbectomized animals displayed increases in irritability to handling, enhanced horizontal activity in the open field, and a deficit in passive-avoidance learning. Animals with lateral olfactory bulb lesions showed an increase in muricidal behavior. Although there were significant intragroup postoperative weight losses, there were no significant differences between groups. Damage to the vomeronasal system alone was not involved in any of the measured behaviors.
\end{abstract}

Many studies have demonstrated that complete removal of the olfactory bulbs $(\mathrm{OB})$ in rats results in a variety of behavioral changes, including increases in mouse killing (Malick, 1970; Thorne, Aaron, \& Latham, 1973, 1974; Thorne, Bracy, \& McNally, 1980; Yoshimura \& Ueki, 1981 ) and increased activity in the open field (Burge \& Edwards, 1976; Klein \& Brown, 1969; Riezen, Schnieden, \& Wren, 1977; Sieck, 1972; Thorne et al., 1980). Hyperirritability has been reported (e.g., Douglas, Isaacson, \& Moss, 1969; Malick, 1970) but may require damage beyond the OB to be seen (Cain, 1974; Thorne et al., 1974). Bulbectomized rats also exhibit relatively poor acquisition of passive avoidance (Broekkamp, Garrigou, \& Lloyd, 1980; Elkins, Frazer, \& Hobbs, 1977; Riezen et al., 1977; Sieck, 1972).

Removal of the OB destroys not only input from the main $\mathrm{OB}$, but also all input from the accessory olfactory bulbs (AOB). The olfactory system comprises the primary olfactory system and the vomeronasal system (Scalia \& Winans, 1975; Winans \& Scalia, 1970).

The primary olfactory system consists of olfactory receptors, olfactory bulbs, and other forebrain areas; the vomeronasal system consists of the vomeronasal organs, vomeronasal nerves (VNN), accessory olfactory bulbs, and other connected forebrain structures. Although the pathways of the two systems are closely associated, the main and accessory bulbs maintain anatomically separate connections with different structures in the brain (Scalia \& Winans, 1975; Winans \& Scalia, 1970).

The AOB has been shown to be critically involved in rodent reproductive behavior (Bean, 1982; Meredith, Marquis, O'Connell, \& Stern, 1980; Powers, Fields, \& Winans, 1979). Male hamsters' mating behavior was

This research was supported in part by an institutional grant from NSF to MSU. A special note of thanks is extended to Sarah S. Winans for her assistance and encouragement over the years. Send reprint requests to: B. Michael Thorne, Drawer PF, Mississippi State University, Mississippi State, MS 39762. found to be disturbed after damage to the vomeronasal system, whereas this was not the case after OB damage (Powers \& Winans, 1975; Winans \& Powers, 1977). Male garter snakes with complete transections of the primary olfactory nerve were found to court and copulate, whereas snakes with complete vomeronasal nerve transections did not (Kubie, Vagvolgyi, \& Halpern, 1978). A recent study (Wysocki, Nyby, Whitney, Beauchamp, \& Katz, 1982) showed removal of the vomeronasal organ disturbed male mouse ultrasonic vocalizations.

It is also possible that damage to the $\mathrm{AOB}$ may result in some or all of the behavior changes seen after OB removal. Studies employing zinc sulfate (ZS) treatment as a control have often produced results that may be interpreted as providing evidence for AOB involvement in the behavior changes seen after complete removal of the $\mathrm{OB}$. For example, OB removal has resulted in increased muricide and irritability, an increase not seen in rats treated with ZS (Cain \& Paxinos, 1974; Christenson, Wallen, Brown, \& Glickman, 1973; Powers \& Winans, 1973). It has been assumed that ZS treatment depresses OB function without affecting the AOB (Powers \& Winans, 1973), and, if this is true, it would imply either that it is damage to the AOB which produces increased muricide and irritability or that it is a combination of damage to the $A O B$ and damage to the $O B$ that is responsible.

However, the assumption that ZS treatment completely depresses the function of the main OB system may be unfounded. Sieck and Baumbach (1974) found that behavioral changes in rodents treated with ZS were not due to anosmia but rather to transient illness caused by the chemical.

In preliminary research from this laboratory, LongEvans hooded rats were subjected to OB removal, cuts of the VNN, or control operations and tested for muricidal behavior, irritability to handling and open-field activity. Bulbectomy resulted in increased muricide, increased rearing in the open field, and a failure to gain 
weight in comparison with control subjects. Cuts of the VNN (i.e., deafferentation of the AOB) had no effect on any of the behaviors measured. Despite the apparent noninvolvement of the AOB, it still could be argued that the combined destruction of the main $\mathrm{OB}$ and the $\mathrm{AOB}$ is responsible for the constellation of changes seen after $\mathrm{OB}$ removal. The effects of $\mathrm{OB}$ damage without damage to either the VNN or the AOB or both were not assessed in this preliminary work.

The present study was designed to replicate and extend the preliminary findings. Specifically, we assessed weight gain, muricidal behavior, open-field activity, handling characteristics, and passive-avoidance learning in LongEvans hooded rats subjected to complete OB removal, VNN cuts, damage to the main OB which avoided both the $\mathrm{VNN}$ and the AOB, or control operations.

\section{METHOD}

\section{Subjects}

The subjects were 46 adult Long-Evans male hooded rats taken from the breeding stock maintained by the Psychology Department at Mississippi State University. The average weight per animal was $543.4 \mathrm{~g}$ (range 379-652 g). All animals were multiply housed until approximately $24 \mathrm{~h}$ before surgery, at which time they were placed in single cages measuring $17.78 \times 25.40 \times 17.78 \mathrm{~cm}$. Adlib food and water conditions were in effect throughout the study. A 12:12 light-dark cycle was in effect in the housing and testing rooms.

The rats were assigned randomly to one of four operative groups: Group OC, operated control animals: Group $\mathrm{COB}$, subjects receiving OB removal; Group VNN, animals receiving cuts of the vomeronasal nerves; Group $\mathrm{LOB}$, subjects receiving lateral $\mathrm{OB}$ damage. Either because of death or inaccurate lesions, 14 animals were dropped from the study ( 2 from Group COB, 8 from Group LOB, and 4 from Group VNN), leaving 32 animals, 8 in each group.

\section{Apparatus}

Open-field activity was assessed in a $76.2 \times 76.2 \times 25.4 \mathrm{~cm}$ box whose interior was painted flat black. The floor was divided into 25 equal squares, and wire mesh covered the top.

Passive-avoidance learning and testing took place in two chambers connected by a guillotine door. The anterior chamber measured $24.7 \times 12.5 \times 30.5 \mathrm{~cm}$, and had a $15-\mathrm{W}$ electric light bulb positioned near the top of the wall opposite the guillotine door. The posterior chamber measured $33.0 \times 26.5 \times 29.0 \mathrm{~cm}$, and it had a grid floor through which it was possible to pass an electric current by using a shock generator (Lafayette Instruments, Inc.). The interiors of both chambers were painted flat black.

\section{Surgery and Histology}

After being weighed, all animals were deeply anesthetized with an ip injection of chloral hydrate solution and were given an im injection of $0.2 \mathrm{cc}$ Duricilin. Their heads were shaved and secured in the headholder from a Baltimore stereotaxic instrument. With the head in a horizontal orientation, the scalp was reflected and a section of bone overlying the olfactory bulbs was removed in Group COB, LOB, and VNN subjects. In Group COB rats, a cut was made immediately rostral to the frontal cortex separating the $\mathrm{OB}$ from the rest of the brain. All tissue anterior to the cut was removed by subpial suction.

For Group VNN animals, the large venous sinus between the main bulbs was visualized and served as a guide for the nerve cuts. Microscissors mounted in the electrode carrier from a Baltimore stereotaxic instrument were positioned over the sinus with a 1-mm opening between the blades and manually lowered approximately $3 \mathrm{~mm}$ into the bulbs. The blades were then closed and the scissors retracted. Bleeding of the sinus was controlled by gentle pressure.

In the case of the LOB group, after the bulbs were exposed, a sagittal cut was made approximately in the middle of each bulb and extending the length of the bulb. All tissue lateral to the cut, away from the midline, was gently aspirated.

After each operation, the wound was closed with autoclips, and the animal was returned to its cage for recovery. All subjects were given 7 days to recover.

Approximately $24 \mathrm{~h}$ after the last day of testing, the experimental animals were weighed and sacrificed with an overdose of sodium pentobarbital. The tops of the skulls were removed, and the heads were fixed in a $10 \%$ formalin solution for at least $48 \mathrm{~h}$ prior to removal of the brains. The lesions of the animals in Groups COB and LOB were reconstructed on line drawings of the dorsal surface of a rat brain, and the reconstructions were used to compute the percentage of damage to the bulbs and to rank the animals in the groups in terms of extent of damage.

The damage produced in Group VNN and Group LOB animals was assessed by study of the horizontal sections showing the main and accessory bulbs. Each brain was frozen with a histofreeze, and slices approximately $100 \mu$ thick were made with a sliding microtome. Brain sections were placed on glass slides and projected, after $10 \mathrm{X}$ enlargement, onto photographic paper. Rats in Group VNN were ranked in terms of extent of damage using the photographs.

\section{Procedure}

On Postoperative Day 7, a 20-min, 24-h test of muricidal behavior was given. In the test, an albino mouse was placed into the cage of each rat, and the incidence of killing and latency to kill were recorded. At the end of $24 \mathrm{~h}$, any live mice or the remains of any dead ones were removed from the cage. Any kills taking place after the 20-min observation period were assigned a 24-h latency. All testing took place during the light portion of the light-dark cycle.

On Postoperative Days 8-11, handling tests were administered. With a clipboard covering its top, the cage was carried from the cage rack to the table on which the handling test was conducted. A 5-component scale was administered. The components were: (1) reaction to perioral pencil presentation; (2) reaction to a pencil tap on the flank; (3) ease of capture; (4) ease of handling; and (5) amount of vocalization. Each component was rated on a 4-point scale (0-3), and each animal was given a daily score based on the summed ratings. The length of the test was $1 \mathrm{~min}$, and the components were administered in the order listed.

Activity was assessed in the open-field apparatus immediately following the handling test. Each animal was placed onto the center square, and the number of squares crossed and the number of rearings (standing on the hind legs) were recorded during a 1-min period. The apparatus was cleaned frequently, and the order of testing was varied daily.

Frequent interobserver reliability measurements were made by having an independent observer score the handling test and openfield activity. The reliability for the summed daily handling scores was $r=.86, p<.001$, and reliability for open-field activity was even higher (horizontal, $r=.99, p<.001$; vertical, $r=.95$, $\mathrm{p}<.001)$.

On Postoperative Day 12, passive-avoidance training was given. Training consisted of placing each rat into the lighted anterior compartment. After a 3-sec period, the door was raised to allow the rat to enter the unlighted posterior chamber, and latency to leave the lighted chamber was recorded. Entry into the darkened compartment resulted in the lowering of the guillotine door and the application of a 3-sec, $1 \mathrm{~mA}$ footshock. The subject was then removed from the apparatus and returned to its cage to await retention testing.

Twenty-four hours after training, each rat was placed into the anterior chamber, the guillotine door opened, and the latency to 
enter the darkened chamber recorded. The retention test was terminated either upon the animal's entry into the posterior compartment or after the animal had remained in the lighted chamber for $3 \mathrm{~min}$.

In all behavioral measures throughout the study, the observer was unaware of the treatment to which each subject belonged. This was done to help ensure the elimination of experimenter bias.

\section{RESULTS}

\section{Histology}

Animals in Group COB sustained essentially complete removal of the OBs rostral to the frontal area, with 5 rats receiving slight bilateral frontal damage. One rat received damage to the dorsal half of the bulb only and was excluded from the study; another animal died before test- ing started. The average damage to the OBs rostral to the frontal area was $88.5 \%$ (range $84 \%-92 \%$ ).

Subjects in the LOB group received a sagittal cut to the OBs, and all tissue lateral to the cut was removed by subpial suction. The removed portion of the OBs included the following: the external plexiform layer, the glomerular layer, the mitral cell layer, and the internal granule cell layer. Several animals received slight bilateral frontal damage and/or slight unilateral damage to the internal granule cell layer of the AOB. Eight animals were excluded from the study because the damage sustained was found to involve extensively the VNN and/or AOB. The average damage to the OBs rostral to the frontal area was $55.5 \%$ (range $42 \%-68 \%$ ). Figure 1 shows representative lesions from Group LOB subjects.

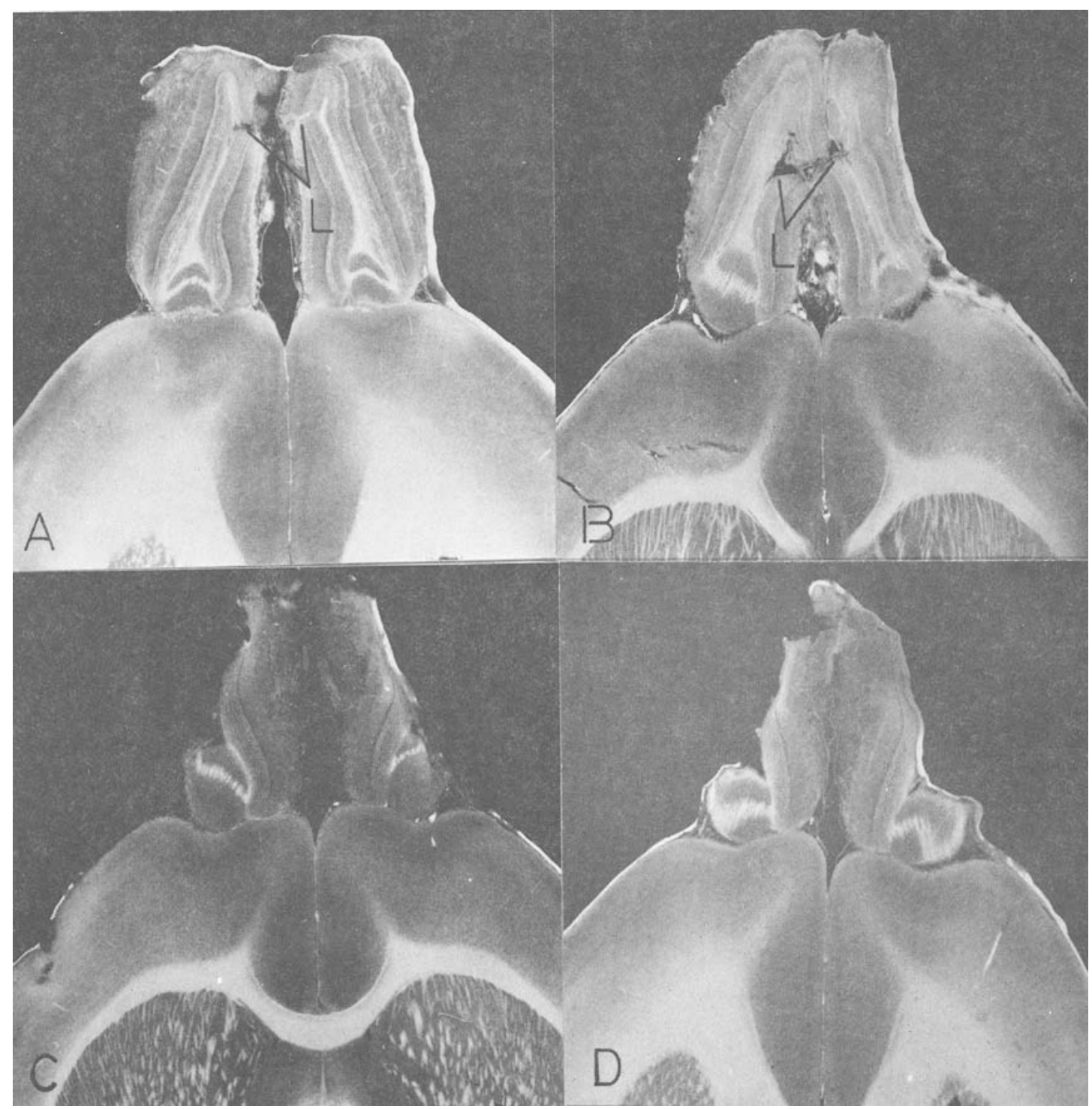

Figure 1. Photographs of unstained sections showing typical lesions of rats from Groups VNN (A and B) and LOB (C and D). $\mathbf{L}$ = lesion. 
Table 1

Average Preoperative Weight and Weight at Sacrifice

\begin{tabular}{lccccc}
\hline & \multicolumn{2}{c}{$\begin{array}{c}\text { Preoperative } \\
\text { Weight }\end{array}$} & & \multicolumn{2}{c}{ Weight at Sacrifice } \\
\cline { 2 - 3 } Group & Mean & SE & & Mean & SE \\
\hline OC & 558.25 & \pm 28.41 & & 509.63 & \pm 22.50 \\
COB & 544.88 & \pm 21.88 & & 505.00 & \pm 18.06 \\
LOB & 544.25 & \pm 23.01 & & 515.38 & \pm 20.49 \\
VNN & 526.25 & \pm 35.78 & & 492.63 & \pm 26.08 \\
\hline
\end{tabular}

Rats in Group VNN received cuts at the level of the $A O B$, extending from the medial surface of the bulbs to the internal granule cell layer of the main OB. Since the VNN traverse the medial surface of the $O B$ in the rat (McCotter, 1912), the cuts sustained in this group would have severed the nerves completely. In addition, inspection of the unstained sections revealed complete loss of the glomerular layer of the AOB in most of the animals. Winans and Powers (1977) used the loss of the glomerular layer and its replacement by gliosis to indicate complete sectioning of the VNN in hamsters. Four rats that received extensive damage to the main OBs were excluded. Representative lesions from Group VNN subjects are shown in Figure 1.

\section{Weight}

A one-way analysis of variance revealed no significant differences between the groups in either preoperative weight or weight at sacrifice. The results are summarized in Table 1.

Within-group comparisons revealed that all groups had significant losses in weight over the course of the study [Group OC, $\mathrm{t}(7)=3.30, \mathrm{p}<.013$; Group COB, $\mathrm{t}(7)=$ $6.60, \mathrm{p}<.001 ;$ Group LOB, $\mathrm{t}(7)=3.01, \mathrm{p}<.02$; Group VNN, $t(7)=2.90, p<.02]$.

\section{Muricide}

Results of an overall test of significance indicated intergroup differences in mouse killing $\left[\chi^{2}(\mathrm{~N}=32)=\right.$ $9.026, p<.029]$. Using the Fisher exact probability test, it was found that Group LOB differed significantly from both Group OC and Group VNN ( $p=.038$ ) but not from Group COB. The percentage of killers in each group was: Groups $\mathrm{OC}$ and VNN, 0\%; Group $\mathrm{COB}, 25 \%$; and Group LOB, 50\%.

\section{Handling}

Analysis of the summed 4-day scores showed significant intergroup differences $\left[\chi^{2}(\mathrm{~N}=32)=10.82, \mathrm{p}=\right.$
.013]. Animals in Group COB were significantly more reactive than rats in any of the other groups (COB vs. $\mathrm{OC}, \mathrm{z}=-2.27, \mathrm{p}=.023$; COB vs. LOB, $\mathrm{z}=-2.669$, $\mathrm{p}=.008 ; \mathrm{COB}$ vs. VNN, $\mathrm{z}=-2.763, \mathrm{p}=.006)$. The group medians were as follows: Group OC, 2.00; Group COB, 5.00; Group LOB, 1.75; and Group VNN, 1.50. There were no significant correlations between extent of damage and handling.

\section{Open-Field Activity: Horizontal}

An overall test performed on the summed 4-day scores revealed significant between-group differences $\left[\chi^{2}(N=\right.$ $32)=7.974, p=.047]$. Further analysis indicated that Group COB rats were more active than Group OC animals $(\mathrm{z}=-2.995, \mathrm{p}=.003)$. Differences between Group COB and Groups LOB and VNN approached the value required for significance $(\mathrm{COB}$ vs. $\mathrm{LOB}, \mathrm{z}=$ $-1.841, \mathrm{p}=.066$; COB vs. VNN, $\mathrm{z}=-1.785, \mathrm{p}=$ $.074)$. The medians and ranges for horizontal and rearing activity are shown in Table 2 . No significant correlations were found between extent of damage and horizontal activity.

\section{Open-Field Activity: Rearing}

Although there were fairly large differences in group medians, a comparison of the summed 4-day scores did not indicate significant differences. Group medians and ranges are shown in Table 2 . The correlation between extent of damage and rearing was not significant.

\section{Passive Avoidance}

Despite large differences in medians, there were no significant intergroup differences on latency to leave the anterior chamber on the training trial. One subject from Group VNN was excluded from the passive-avoidance test because it failed to enter the dark chamber within $180 \mathrm{sec}$. Medians and ranges (in seconds) to leave the anterior chamber are shown in Table 3. Open-field activity (horizontal) was negatively correlated with latency to leave on the training trial $(\mathrm{r}=-.399, \mathrm{p}=.013)$.

Significant intergroup differences were found on the 2 nd day $\left[\chi^{2}(\mathrm{~N}=31)=16.913, \mathrm{p}=.001\right]$. Rats in Group COB had shorter latencies to leave the anterior chamber than did animals in any of the other groups (COB vs. OC, $\mathrm{z}=-2.348, \mathrm{p}=.001$; COB vs. LOB, $\mathrm{z}=$ $-3.165, \mathrm{p}=.002$; COB vs. VNN, $\mathrm{z}=-3.033, \mathrm{p}=$ .002 ). Open-field activity (horizontal) was negatively correlated with exit latency on the 2 nd day $(r=-.324, p=$ .038 ). That is, greater horizontal activity was associated with shorter latencies to leave the anterior chamber.

Table 2

Medians (Md) and Ranges (R) of Open-Field Activity

\begin{tabular}{lccccccccc}
\hline & \multicolumn{1}{c}{} & \multicolumn{1}{c}{ OC } & \multicolumn{2}{c}{ COB } & \multicolumn{2}{c}{ LOB } & \multicolumn{2}{c}{ VNN } \\
\cline { 2 - 10 } Activity & $\mathrm{Md}$ & $\mathrm{R}$ & $\mathrm{Md}$ & $\mathrm{R}$ & $\mathrm{Md}$ & $\mathrm{R}$ & $\mathrm{Md}$ & $\mathrm{R}$ \\
\hline Horizontal & 68.5 & $20-107$ & 107.5 & $85-162$ & 61.0 & $40-153$ & 58.0 & $25-141$ \\
Rearing & 17.5 & $6-29$ & 28.0 & $17-42$ & 19.5 & $15-31$ & 24.5 & $4-30$ \\
\hline
\end{tabular}


Table 3

Medians (Md) and Ranges (R) in Seconds Taken to Leave the Anterior Chamber

\begin{tabular}{lcccccccc}
\hline & \multicolumn{10}{c}{ Groups } \\
\cline { 2 - 11 } & Md & R & Md & R & Md & R & Md & R \\
\hline Day 1 & 16.1 & $3.0-43.4$ & 7.1 & $1.0-28.4$ & 2.9 & $1.6-26.8$ & 3.2 & $1.0-54.2$ \\
Day 2 & 96.4 & $7.4-180.0$ & 1.7 & $1.0-7.4$ & 18.0 & $2.0-180.0$ & 85.0 & $22.0-180.0$ \\
Difference & -135.2 & $-163.4-0.6$ & 5.3 & $0.0-26.8$ & -11.7 & $-177.2-0.2$ & -74.4 & $-177.2-0.6$ \\
\hline
\end{tabular}

Significant intergroup differences were found in the difference in latency between the training and testing trials $\left[\chi^{2}(\mathrm{~N}=31)=14.549, \mathrm{p}=.002\right]$. Animals in Group $\mathrm{COB}$ had smaller latency differences than animals in any of the other groups (COB vs. OC, $\mathrm{z}=-3.046$, $\mathrm{p}=.002 ; \mathrm{COB}$ vs. $\mathrm{LOB}, \mathrm{z}=-3.055, \mathrm{p}=.002 ; \mathrm{COB}$ vs. VNN, $z=-2.893, p=.004)$.

Open-field activity (rearing) was significantly correlated with all three passive-avoidance learning measures: 1st day latency $(\mathrm{r}=-0.520 . \mathrm{p}=.001) ; 2$ nd day latency $(\mathrm{r}=-.498, \mathrm{p}=.002)$; difference between $1 \mathrm{st}$ and $2 \mathrm{nd}$ day latency $(r=.444, p=.006)$. There were no significant correlations between extent of damage and any of the passive-avoidance learning measures.

\section{DISCUSSION}

Although previous studies (e.g., Malick, 1970; Thorne et al., 1973, 1974; Thorne et al., 1980; Yoshimura \& Ueki, 1981) have shown an increase in mouse killing in rats with complete olfactory bulb removal, the animals in Group $\mathrm{COB}$ in the present study did not have an increased incidence of mouse killing. On the other hand, animals in Group LOB were found to differ significantly from the other groups in muricidal behavior.

Denervation of the AOB by cutting the vomeronasal nerves did not cause an increase in muricidal behavior. Thus, it appears that damage to the main $\mathrm{OB}$ alone is responsible for the increase in muricide often reported as a consequence of $O B$ lesions. There is no obvious explanation for our failure to find an increase in muricide in Group COB, and it may be worth noting that, other than Group LOB rats, the only rats that killed in this study were in Group COB.

In the present study, animals in Group $\mathrm{COB}$ displayed increased irritability to handling, a finding that agrees with several other studies (e.g., Douglas et al., 1969; Malick, 1970; Riezen et al., 1977). However, it should be noted that even though there were significant differences, the mean of the summed 4-day scores in Group COB was only 6.625 (range from 1 to 16 , with a maximum possible score of 60), and the animals in this study were not nearly as hard to handle as those described by Douglas et al., Malick, and others.

The finding of increased irritability is not in agreement with some research from this laboratory (e.g., Thorne et al., 1973, 1974; Thorne et al., 1980; Thorne \& Linder, 1971) and from other laboratories (Bandler \& Chi, 1972;
Phillips, 1970). It was suggested by Thorne et al. (1974) that damage posterior to the main $\mathrm{OB}$ and ventral to the frontal area appeared to be responsible for the occurrence of irritability, but this was not involved in the present study, since COB animals had damage limited to the OB rostral to the frontal cortex.

In agreement with previous research (e.g., Burge \& Edwards, 1976; Klein \& Brown, 1969; Riezen et al., 1977; Sieck, 1972; Thorne et al., 1980), completely bulbectomized rats showed an increase in open-field activity. Animals in Group $\mathrm{COB}$ exhibited increased horizontal activity, whereas damage either to the VNN alone or to the main OB alone (Group LOB) did not cause any change.

In accordance with previous studies (Broekkamp et al., 1980; Elkins et al., 1977; Riezen et al., 1977; Sieck, 1972), completely bulbectomized rats had a significant deficit in passive-avoidance learning. The difference in latency between the training and testing trials was found to differ significantly among the groups, with animals in Group COB having smaller latency differences or shorter latencies than animals in any of the other groups. Again, damage to neither the $\mathrm{VNN}$ alone nor the main $\mathrm{OB}$ alone (Group LOB) caused a deficit in passive-avoidance learning.

The significant correlations between open-field activity and passive-avoidance learning measures support previous findings (e.g., Riezen et al., 1977; Sieck, 1973) indicating that an increase in locomotor activity is related to deficits in passive-avoidance learning in bulbectomized animals. That is, it is possible that the passive-avoidance deficit is a consequence of enhanced activity rather than a memory defect per se.

Edwards, Bryan, and Florian (1979) reported that OB removal did not have any effect on the rat's ability to eat and drink and that the rat was able to maintain its normal body weight. However, they used only one group in their study, and no mention was made of statistical comparisons with control operates. In the present study, although a one-way analysis of variance did not reveal any significant intergroup differences in either preoperative or postoperative weight, a within-group comparison revealed significant losses in weight in all groups over the course of the study. Since the only common factor among all four groups was the operation itself, it is likely that the physical trauma and associated reactions to surgery, rather than any of the damage inflicted on the specific structures under examination, were responsible for the weight loss. Thus, the results of the present study agree with those 
of Edwards et al., and neither olfactory system seems to be essential for the regulation of food consumption and/or body weight in the rat.

The olfactory bulb is not a discrete structure, although it is often treated as such in studies employing bilateral bulbectomy (Alberts, 1974). Thus, it is virtually impossible to perform a lesion by aspiration that is limited solely to the bulbs. Other structures likely to receive damage in operations aimed at the bulbs include the anterior olfactory nucleus (AON), the lateral olfactory tracts, and the accessory olfactory bulbs. The present study was designed to assess the contribution of deafferentation of the AOB to the constellation of behavior changes often seen following bulbectomy.

The results were unequivocal. To the extent that the VNN cuts successfully eliminated input to the $A O B$, there was no evidence that deafferentation of the AOB plays a role in the increases in muricide, hyperreactivity, increased open-field activity, or deficient passive-avoidance learning often noted in bulbectomized rats. On all measures, Group VNN rats were indistinguishable from controls.

Rats with damage limited primarily to the main olfactory bulb (Group LOB) differed from controls only in the propensity to kill mice. Since LOB rats did not differ from controls in irritability, the enhanced killing cannot be explained by "an anosmia that is combined with a more or less marked hyperreactivity" (Karli, 1981). However, Karli's hypothesis of predatory killing resulting from a reaction to stimulus novelty may be relevant. That is, because of anosmia or hyposmia, the rat with OB damage fails to detect the familiar odor of the mouse (familiar because of similar housing and feeding conditions) and treats it as a novel stimulus.

Complete bulbectomy producing damage to the main $\mathrm{OB}, \mathrm{AOB}$, and probably to the anterior olfactory nucleus resulted in the most dramatic changes in behavior relative to the controls. Thus, rats in Group COB were hyperreactive, more active in the open-field test, and grossly deficient on the passive-avoidance task. Since neither damage to the $\mathrm{OB}$ alone nor deafferentation of the $\mathrm{AOB}$ produced any of the changes noted in Group $\mathrm{COB}$ animals, either the combined damage or damage to some structure relatively spared in Groups LOB and VNN must have been responsible. The most likely candidate for such incidental damage is the AON (Sieck, 1973), possibly in conjunction with the more rostral damage (Albert \& Walsh, 1982). Future research should be aimed at assessing the role of the AON in the behavior changes seen in the present study.

\section{REFERENCES}

Albert, D. L., \& WAlSh, M. L. (1982). The inhibitory modulation of agonistic behavior in the rat brain: A review. Neuroscience \& Biobehavioral Reviews, 6, 125-143.

AlBerts, J. R. (1974). Producing and interpreting experimental olfactory deficits. Physiology \& Behavior, 12, 657-670.
BANDleR, R. J., \& CHI, C. C. (1972). Effects of olfactory bulb removal on aggression: A reevaluation. Physiology \& Behavior, 8, 207-211.

BEAN, N. J. (1982). Olfactory and vomeronasal mediation of ultrasonic vocalizations in male mice. Physiology \& Behavior, 28, 31-37.

BroekKamp, C. L., Garrigou, D., \& Lloyd, K. G. (1980). Serotoninmimetic and antidepressant drugs on passive-avoidance learning by olfactory bulbectomized rats. Pharmacology, Biochemistry \& Behavior, 13, 643-646.

Burge, K. G., \& EDwARDS, O. A. (1976). Olfactory bulb removal results in elevated spontaneous locomotor activity in mice. Physiology \& Behavior, 16, 83-89.

CAIN, D. P. (1974). Olfactory bulbectomy: Neural structures involved in irritability and aggression in the male rat. Journal of Comparative \& Physiological Psychology, 86, 213-220.

CAIN, D. P., \& Paxinos, G. (1974). Olfactory bulbectomy and mucosal damage: Effects on copulation, irritability, and interspecific aggression in male rats. Journal of Comparative \& Physiological Psychology, 86, 202-212.

Christenson, T., Wallen, K., Brown, B. A., \& Glickman, S. E. (1973). Effects of castration, blindness and anosmia on social reactivity in the male Mongolian gerbil (Meriones unguiculatus). Physiology \& Behavior, 10, 989-994.

Douglas, R. J., IsaAcson, R. L., \& Moss, R. L. (1969). Olfactory lesions, emotionality and activity. Physiology \& Behavior, 4, 379-381.

Edwards, D. A., Bryan, B., \& Florian, V. A. (1979). Olfactory system involvement in the recovery of feeding and drinking after lateral hypothalamic damage in the rat. Physiology \& Behavior, 22, 1163-1169.

Elkins, R. L., Fraser, J., \& Hobbs, S. H. (1977). Differential olfactory bulb contribution to baitshyness and place avoidance learning. Physiology \& Behavior, 19, 787-793.

KARLI, P. (1981). Conceptual and methodological problems associated with the study of brain mechanisms underlying aggressive behaviour. In P. F. Brain \& D. Benton (Eds.), The biology of aggression. The Netherlands: Sijthoff \& Noordhoff.

KLEIN, D., \& Brown, T. S. (1969). Exploratory behavior and spontaneous alternation in blind and anosmic rats. Journal of Comparative \& Physiological Psychology, 68, 107-110.

Kubie, J. L. Vagvolgyi, A., \& Halpern, M. (1978). Roles of the vomeronasal and olfactory systems in courtship behavior of male garter snakes. Journal of Comparative \& Physiological Psychology, 92, 627-641.

Malick, J. B. (1970). A behavioral comparison of three lesion-induced models of aggression in the rat. Physiology \& Behavior, 5, 679-681.

MCCotTER, R. E. (1912). The connection of the vomeronasal nerves with the accessory olfactory bulb in the opossum and other mammals. The Anatomical Record, 6, 299-318.

Meredith, M., Marquis, O. M., O’Connell, R. J., \& Stern, F. L. (1980). Vomeronasal pump: Significance for male hamster sexual behavior. Science, 207, 1224-1226.

Phillips, S. D. (1970). Effects of olfactory bulb ablation on visual discrimination. Physiology \& Behavior, 5, 13-15.

Powers, J. B., Fields, R. B., \& Winans, S. S. (1979). Olfactory and vomeronasal system participation in male hamsters' attraction to female vaginal secretions. Physiology \& Behavior, 22, 77-84.

Powers, J. B., \& Winans, S. S. (1973). Sexual behavior in peripherally anosmic male hamsters. Physiology \& Behavior, 10, 361-368.

Powers, J. B., \& Winans, S. S. (1975). Vomeronasal organ: Critical role in mediating sexual behavior of the male hamster. Science, 187 , 961-963.

Riezen, H. van, Schnieden, H., \& Wren, A. F. (1977). Olfactory bulb ablation in the rat: Behavioural changes and their reversal by antidepressant drugs. British Journal of Pharmacology, 60, 521-528.

Scalia, F., \& Winans, S. S. (1975). The differential projections of the olfactory bulb and accessory olfactory bulb in mammals. Journal of Comparative Neurology, 161, 31-56.

SiECK, M. H. (1972). The role of the olfactory system in avoidance learning and activity. Physiology \& Behavior, 8, 705-710.

SIECK, M. H. (1973). Selective olfactory system lesions in rats and 
changes in appetitive and aversive behavior. Physiology \& Behavior, 10, 713-739.

Sieck, M. H., \& Baumbach, H. D. (1974). Differential effects of peripheral and central anosmia producing techniques on spontaneous behavior patterns. Physiology \& Behavior, 13, 407-425.

Thorne, B. M., Aaron, M., \& Latham, E. E. (1973). Effects of olfactory bulb ablation upon emotionality and muricidal behavior in four rat strains. Journal of Comparative \& Physiological Psychology, 84, 339-344.

Thorne, B. M., Aaron, M., \& Latham, E. E. (1974). Olfactory system damage in rats and emotional, muricidal, and rat pup killing behavior. Physiology \& Behavior, 2, 157-163.

Thorne, B. M., Bracy, O. L., \& McNally, S. (1980). The effects of simultaneous and serial lesions of the olfactory bulbs on muricide, irritability, and open-field activity in Long-Evans female rats. Bulletin of the Psychonomic Society, 15, 143-146.

ThORNE, B. M., \& LiNDER, L. H. (1971). No change in emotionality of rats following bulbectomy. Psychonomic Science, 24, 207-208.
Winans, S. S., \& Powers, J. B. (1977). Olfactory and vomeronasal deafferentation of male hamsters: Histological and behavioral analysis. Brain Research, 126, 325-349.

Winans, S. S., \& SCalia, E. (1970). Amygdaloid nucleus: New afferent input from the vomeronasal organ. Science, 170, 330-332.

Wysocki, C. J., Nyby, J., Whitney, G., Beauchamp, G. K., \& Katz, Y. (1982). The vomeronasal organ: Primary role in mouse chemosensory gender recognition. Physiology \& Behavior, 29, 315-327.

Yoshimura, H., \& UeKI, S. (1981). Mouse-killing and hyperemotionality in rats induced by three different kinds of experimental manipulations: A comparative study. Physiological Psychology, 9, 269-275.

(Manuscript received June 24, 1985; revision accepted for publication December 26, 1985.) 